\title{
Is degenerative calcification of the native aortic valve similar to calcification of bioprosthetic heart valves?
}

\author{
Tirone E. David, MD \\ Joan Ivanov, $\mathrm{PhD}$
}

See related articles on pages 965 and 969.

From the Department of Surgery, University of Toronto, Toronto, Ontario, Canada.

Received for publication April 23, 2003; accepted for publication April 30, 2003.

Address for reprints: Tirone E. David, MD, Department of Surgery, University of Toronto, 200 Elizabeth St, 13EN219, Toronto, Ontario M5G 2C4, Canada (E-mail: tirone. david@uhn.on.ca).

J Thorac Cardiovasc Surg 2003;126:939-41

Copyright $(\odot 2003$ by The American Association for Thoracic Surgery

$0022-5223 / 2003 \$ 30.00+0$

doi:10.1016/S0022-5223(03)00731-1

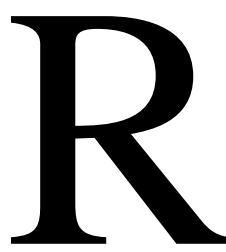

ecent epidemiologic, histologic, and molecular studies suggest that the pathogenesis of degenerative disease of the native aortic valve resembles that of atherosclerosis. ${ }^{1-3}$ The initial aortic valve lesion, valve sclerosis, is related to infiltration and oxidation of lipoproteins similar to that seen in atherosclerosis. ${ }^{2,3}$ Calcification, one of the principal features of degenerative disease of the native aortic valve, is also present in atherosclerotic plaques. ${ }^{2,3}$ Not surprisingly, retrospective studies showed an association between risk factors for coronary artery disease, such as male sex, cigarette smoking, high blood pressure, diabetes, and hyperlipidemia, and progression of aortic valve stenosis. ${ }^{4}$ However, a recent prospective, population-based epidemiologic study showed no correlation between coronary artery risk factors and the rate of progression of aortic stenosis. ${ }^{5}$

What many studies have shown more consistently is that treatment with 3-hydroxy-3-methyl-glutamyl coenzyme A reductase inhibitors (statins) reduces the rate of progression of aortic valve stenosis. ${ }^{4-7}$ In most studies the slower rate of calcification of the aortic cusps produced by statins did not appear directly related to the reduction of serum cholesterol level but rather caused by its pleiotropic effects. ${ }^{5-7}$ Statins affect a multitude of cellular functions: they increase production of nitric oxide by endothelial cells, reduce inflammatory reactions, decrease secretion of metalloproteins and osteopontin by macrophages, stabilize atherosclerotic plaques, prevent thrombus formation, and have many other less defined effects, such as reducing the risk of dementia. ${ }^{8,9}$

Calcification of the native aortic cusps is a complex and poorly understood process, but it appears to be related to inflammation, infiltration of lipoproteins, and ossification. ${ }^{2,3,10,11}$ Statins probably delay calcification of the native aortic cusps by reducing inflammation and decreasing the deposition of lipoproteins and ossification, as they do in coronary arteries. ${ }^{8,12}$ However, the notion that coronary artery risk factors increase the risk of aortic valve stenosis remains controversial. ${ }^{5,6}$

The pathogenesis of calcification of bioprosthetic heart valves is even less well understood than that of the native aortic valve. Clinical experience with bioprosthetic heart valves far exceeds the scientific knowledge of the interactions between the host and the glutaraldehyde-fixed tissue that makes up the cusps of a bioprosthetic valve. Calcification is the principal cause of failure of first-generation bioprosthetic heart valves, and young age is the single most important determinant of calcification. The mechanism of accelerated calcification in young patients remains largely unknown. It might involve an immune-mediated reaction and an increased adsorption of proteins related to bone formation. ${ }^{13,14}$ The clinical observation that prolonged corticosteroid therapy restricts calcification of bioprosthetic valves in young patients corroborates the notion that immune reaction might play a role in calcific degeneration. ${ }^{15,16}$ These findings suggest that the cross-links between glutaraldehyde and certain immunogenic proteins in the xenograft tissue might be incomplete or short lived. Indeed, it has been shown experimentally that valves stored in glutaraldehyde solutions for a prolonged period are less likely to calcify than those implanted soon after fixation. ${ }^{17}$ Another interesting finding on calcification of bioprosthetic valves is that removal of lipids with certain solvents, such as alcohol, mitigates calcification in experimental animals. ${ }^{18}$ Newer porcine and peri- 


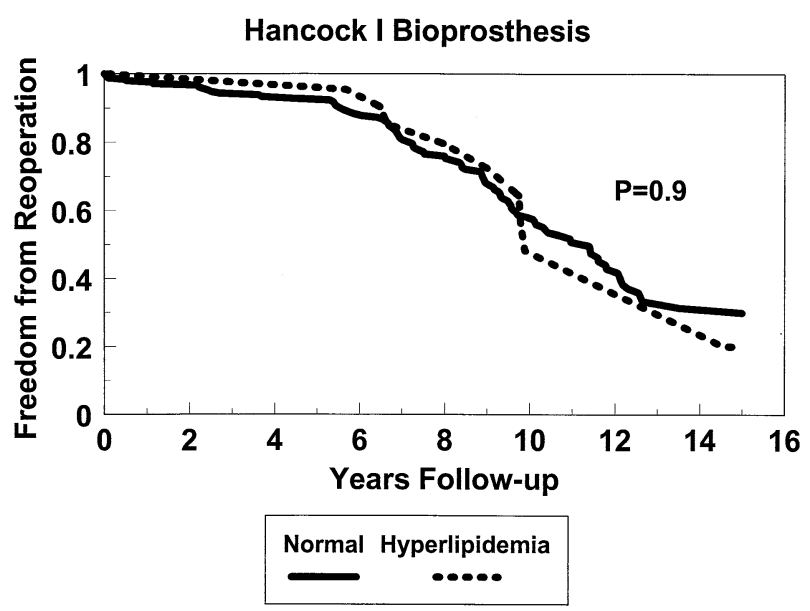

Figure 1. Freedom from reoperation after aortic valve replacement with the Hancock I bioprosthesis in patients with normal and increased cholesterol levels (Stanford University data).

cardial bioprosthetic valves are treated with various agents that are effective in reducing calcification of the cusps, and the failure mode of these newer valves might not be the same as in first-generation bioprostheses. Finally, mechanical stress also plays an important role in bioprosthetic valve durability. Indeed, bioprosthetic valves are more durable in the aortic position than they are in the mitral position. Valve and stent design is important to minimize mechanical stress on the cusps, and that is one of the reasons why the Edwards Perimount valve (Edwards Lifesciences, Irvine, Calif) has proved to be more durable than the Ionescu-Shiley pericardial valve (Shiley, Inc, Irvine, Calif). Inadequate stent design was probably the main reason the Hancock pericardial valve failed prematurely, and the manufacturer (Medtronic, Inc, Minneapolis, Minn) removed it from the market soon after its introduction. ${ }^{19}$

In this issue of the Journal, there are 2 articles on bioprosthetic heart valve failure and coronary artery risk factors. ${ }^{19,20}$ Nollert and colleagues ${ }^{19}$ attempted to establish a relationship between premature failure of the Hancock pericardial valve and risk factors for atherosclerosis. Unfortunately, the study was flawed from several important perspectives. First, risk factors for atherosclerosis were hopelessly confounded with the poorly designed pericardial heart valve. Although it might be argued that the risk factors identified were independent of the bad valve, it is impossible to discern whether the risk factors for atherosclerosis would have had the same association in other types of bioprostheses. Second, there is no clinical, biologic, or sociologic rationale for using 57 years of age as a cutoff point to define an elderly population. This cutoff point was one of convenience only because it defined the median age of the population. Third, the results in Table 1 of that article are only valid if all survivors were followed up at the same

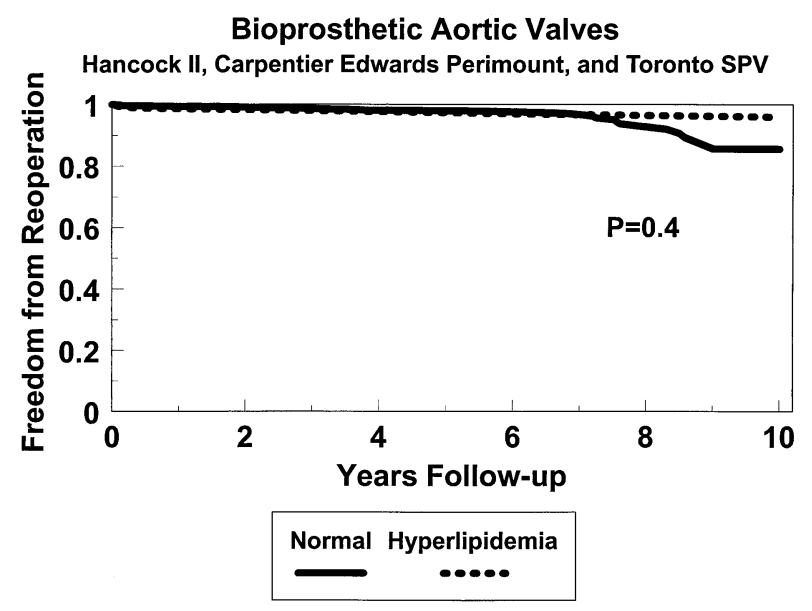

Figure 2. Freedom from reoperation after aortic valve replacement with various bioprosthetic valves in patients with normal and increased cholesterol levels (Toronto General Hospital data).

time (eg, within a 3-month interval). The authors did not provide the risk ratios (RRs) or confidence intervals (CIs) for the independent predictors of reoperation. The rationale for leaving hypertension out of the multivariable models is inappropriate. Finally, the use of reoperation as an end point is potentially biased because of patient selection. A more appropriate outcome would have been to use primary tissue failure at reoperation, autopsy, or echocardiographic evaluation. Elderly patients might not be offered reoperation at the same rate as younger patients.

The study by Farivar and $\mathrm{Cohn}^{20}$ did not corroborate all the findings by Nollert and colleagues ${ }^{19}$ but also suggests that cholesterol plays a role in valve failure of a firstgeneration porcine bioprosthesis. Although the difference in cholesterol levels between the 2 groups was statistically significant, the mean cholesterol value in both groups was within the normal range. No other coronary artery risk factors were found to be associated with an increased risk of bioprosthetic heart valve failure.

In a Cox regression analysis of 653 patients without coronary artery disease who underwent aortic valve replacement with the Hancock I bioprosthesis at Stanford University between 1970 and 1982 (data provided by Dr D. C. Miller), the only independent predictor of reoperation was young age (RR for age, $0.95 ; 95 \% \mathrm{CI}, 0.94-0.96 ; P<.001$ ). Hyperlipidemia was not a significant predictor in this group $(P=.5)$. We also constructed 2 similar age-defined cohorts, using the age cutoff point of the study by Nollert and colleagues. ${ }^{19}$ In the younger patients (age $<58$ years), the independent predictors of reoperation were age (RR, 0.96; 95\% CI, 0.94-0.98; $P=.001)$ and male sex (RR, 1.79; 95\% CI, 1.0-3.1; $P=.037)$. In this cohort hyperlipidemia was not a significant predictor $(P=.7)$. In the older patients age was the only independent predictor of reoperation (RR, 
0.93; 95\% CI, 0.9-1.0; $P=.036)$. Hyperlipidemia was not a predictor $(P=.9)$. Figure 1 depicts the freedom from reoperation in patients with normal or increased cholesterol levels after aortic valve replacement with the Hancock I bioprosthesis.

We performed a Cox regression analysis for reoperation in 913 patients, including those with coronary artery disease, who underwent aortic valve replacement after 1990 at the Toronto General Hospital (Hancock II, n = 426; Carpentier-Edwards Perimount, $\mathrm{n}=215$; Toronto SPV, $\mathrm{n}=$ 272 [St Jude Medical, Inc, St Paul, Minn]). The only significant independent predictor of reoperation was age (RR, 0.95; 95\% CI, 0.92-0.97; $P=.001)$, confirming previous findings that younger patients are more likely to undergo reoperation. Not significant in this model were smoking, hyperlipidemia, sex, renal insufficiency, hypertension, or diabetes. Figure 2 depicts the freedom from reoperation and hyperlipidemia.

Because of numerous confounding factors, neither the data of Nollert and colleagues, ${ }^{19}$ the data of Farivar and Cohn, ${ }^{20}$ our analysis of the Stanford University data, nor our own data prove or disprove that patients with risk factors for atherosclerosis have accelerated bioprosthetic valve failure. In our patients with risk factors for atherosclerosis, it is possible that the probability of valve failure was reduced because most of them were taking statins.

The hypotheses that risk factors for coronary artery disease might accelerate the degeneration of bioprosthetic heart valves and that statins might reduce degeneration are interesting and provocative and certainly deserve further study.

\section{References}

1. Agmon Y, Khandheria BK, Meissner I, et al. Aortic valve sclerosis and aortic atherosclerosis: different manifestations of the same disease? Insights from a population-based study. J Am Coll Cardiol. 2001;38: 827-34.

2. Otto CM, Kuusisto J, Reichenbak DD, Gown AM, O'Brien KD. Characterization of the early lesion of "degenerative" valvular aortic stenosis. Circulation. 1994;90:844-53.

3. O'Brien KD, Reinchenbach DD, Marcovina SM, Kuusisto J, Alpers CE, Otto CM. Apoliproteins B, (a), and E accumulate in the morphologically early lesion of "degenerative" valvular aortic stenosis. Atheroscler Thromb Vasc Biol. 1996;16:523-32.
4. Aronow WS, Ahn C, Kronzon I, Goldman ME. Association of coronary risk factors and use of statins with progression of mild valvular aortic stenosis in older persons. Am J Cardiol. 2001;88:693-5.

5. Bellamy MF, Pellikka PA, Klarich KW, Tajik AJ, Enriquez-Sarano M. Association of cholesterol levels, hydroxymethylglutaryl coenzyme-A reductase inhibitor treatment, and progression of aortic stenosis in the community. J Am Coll Cardiol. 2002;40:1723-30.

6. Palta S, Pai AM, Gill KS, Pai RG. New insights into the progression of aortic stenosis: implications for secondary prevention. Circulation. 2000;101:2497-502.

7. Novaro G, Tiong IY, Pearce BL, Lauer MS, Sprecher DL, Griffin BP. Effect of hydroxymethylglutaryl coenzyme A reductase inhibitors on the progression of calcific aortic stenosis. Circulation. 2001;104: 2205-9.

8. Veillard NR, Mach F. Statins: the new aspirin? Cell Mol Life Sci. 2002;59:1771-86.

9. Zornberg JH, Jick SS, Seshadri S, Drachman DA. Statins and the risk of dementia. Lancet. 2000;356:1627-31.

10. Mohler ER 3rd, Gannon F, Reynolds C, Zimmerman R, Keane MG, Kaplan FS. Bone formation and inflammation in cardiac valves. Circulation. 2001;103:1522-8.

11. Jian B, Narula N, Li Q, Mohler ER, Levy RJ. Progression of aortic valve stenosis: TGF- $\beta 1$ is present in calcified aortic valve cusps and promotes aortic valve interstitial cell calcification via apoptosis. Ann Thorac Surg. 2003;75:457-66.

12. Callister TQ, Raggi P, Cooil B, Lippolis NJ, Russo DJ. Effect of HMG-CoA reductase inhibition on coronary artery disease as assessed by electron-beam computed tomography. N Engl J Med. 1998;339: 1972-8.

13. Human P, Zilla P. Characterization of the immune response to valve bioprostheses and its role in primary tissue failure. Ann Thorac Surg. 2001;71(suppl 5):S385-8

14. Shen M, Marie P, Farge D, et al. Osteopontin is associated with bioprosthetic heart valve calcification in humans. C R Acad Sci III. 1997;320:49-57.

15. Shimizaki Y, Kuraoka S, Takeda F, Watanabe T, Inui K. Mitral valve re-replacement for impaired biprosthesis after 19 years in a patient undergoing steroid treatment. J Heart Valve Dis. 2003;12:45-7.

16. Eishi K, Ishibashi-Ueda $\mathrm{H}$, Nakano $\mathrm{K}$, et al. Calcific degeneration of bioprosthetic aortic valves in patients receiving steroid therapy. J Heart Valve Dis. 1996;5:668-72.

17. Liao K, Frater RWM, LaPietra A, Ciuffo G, Llardi CF, Seifter E. Time-dependent effect of glutaraldehyde on the tendency to calcify of both autolografts and xenografts. Ann Thorac Surg. 1995;60(suppl): S343-7.

18. Ogle MF, Kelly SJ, Bianco RW, Levy RJ. Calcification resistance with aluminum-ethanol treated porcine aortic valve bioprostheses in juvenile sheep. Ann Thorac Surg. 2003;75:1267-73.

19. Nollert G, Miksch J, Kreuzer E, Reichart B. Risk factors for atherosclerosis and the degeneration of pericardial valves after aortic valve replacement. J Thorac Cardiovasc Surg. 2003;126:965-8.

20. Farivar RS, Cohn LH. Hypercholesterolemia is a risk factor for bioprosthetic valve calcification and explantation. $J$ Thorac Cardiovasc Surg. 2003;126:969-76. 